\title{
Effectiveness of omalizumab in a patient with severe asthma and atopic dermatitis
}

\author{
C. Incorvaia1', C. Pravettoni1, M. Mauro2, M.-R. Yacoub33, \\ F. Tarantini4, G.G. Riario-Sforza1
}

ABSTRACT: Effectiveness of omalizumab in a patient with severe asthma and atopic dermatitis. $C$. Incorvaia, C. Pravettoni, M. Mauro, M.-R. Yacoub, F. Tarantini, G.G. Riario-Sforza.

The anti-IgE antibody omalizumab is currently indicated in severe asthma not controlled by standard drug therapy. Recently, new indications for omalizumab were suggested, which include atopic dermatitis (AD), a skin disorder characterized by elevated levels of IgE.

We report the case of a 39-year old woman with severe asthma and severe $\mathrm{AD}$, both resistant to conventional drug treatment. The patient had a IgE level of $\mathbf{1 3 0 4}$ $\mathrm{kU} / \mathrm{L}$, which exceeded the recommended maximum level for treating asthma with omalizumab (stated in $700 \mathrm{Ku} / \mathrm{L}$ ) but was far lower than previously reported in cases of $\mathrm{AD}$ treated with anti-IgE. The treatment consisted of a dose of omalizumab $375 \mathrm{mg}$ every two weeks, and induced a rapid improvement of asthma, with no need of other drugs after three months, along with a progressive decline of severity of AD, which after five months was completely cured.

These findings suggest the usefulness of omalizumab in patients with concomitant severe asthma and $\mathrm{AD}$, also considering the pharmaco-economic balance obtained by withdrawing the multiple drugs used to treat both diseases.

Monaldi Arch Chest Dis 2008; 69: 2, 78-80.

Keywords: Anti-IgE, Omalizumab, Severe asthma, Atopic dermatitis.

1 Pulmonary Rehabilitation Dept., ICP Hospital, Milan,

2 Allergy Dept., Sant'Anna Hospital, Como,

3 Allergy and Rheumatology Unit, IRCCS San Raffaele Hospital, Milan,

${ }^{4}$ Respiratory Clinical Research, Novartis Farma S.p.A., Origgio, Italy.

Correspondence: Cristoforo Incorvaia, Viale Molise, 69 - 20137 Milano, Italy; e-mail cristoforo.incorvaia@fastwebnet.it

\section{Introduction}

IgE antibodies are a main issue in the pathophysiology of allergic diseases [1-4], and the possibility of reducing their level by using the antiIgE drug has long been expected. A recent biologic agent, the recombinant, humanised monoclonal antibody omalizumab, satisfied this prospect [5, 6]. Several controlled clinical trials have demonstrated its safety and efficacy in the treatment of severe allergic asthma not controlled by standard drug therapy with maximal recommended dose [710]; treatment with omalizumab has therefore now been included in the international guidelines for asthma management [11].

Some studies have reported a clear effectiveness also in allergic rhinitis [12-15], but the cost/effectiveness profile suggests its use only in patients with rhinitis concomitant with severe asthma. Other indications to be investigated further are adverse reactions to foods, with a particularly important role in preventing food-induced anaphylaxis [16] and skin disorders such as atopic dermatitis (AD) and IgE-mediated urticaria [17-20]. We report the case of a patient with severe $\mathrm{AD}$ and severe asthma, both conditions successfully treated with omalizumab.

\section{Case report}

We describe the case of a 39-year old woman with severe persistent asthma and $\mathrm{AD}$, resistant to pharmacological treatment, which appeared 13 years ago. The patient was sensitized to grass and Parietaria pollen and actually had worsening of both asthma and atopic dermatitis during the pollen period of such plants, i.e. from April to September in her living area. Eight years before she underwent allergen immunotherapy for grass pollen by subcutaneous route, but she stopped the treatment after the first cycle because of pregnancy. Immunotherapy was restarted in 2004 for both grass and Parietaria pollen by sublingual route and was continuing at the time of our evaluation. Asthma was treated by inhaled fluticasone 1500 $\mathrm{mcg} / \mathrm{die}$, divided in three administrations of 500 $\mathrm{mcg}$, inhaled salmeterol $50 \mathrm{mcg}$ b.i.d., and oral montelukast $10 \mathrm{mg} / \mathrm{day}$, but such treatment was unable to control respiratory symptoms. Only courses of oral corticosteroids were effective in maintaining the asthma under control. In addition, $\mathrm{AD}$ was resistant to conventional topical treatment. A significant improvement was achieved only by a two-month course of cyclosporin, but the disease relapsed six months after the interruption 
of this treatment. We assessed the severity of AD at baseline by the SCORAD index, obtaining a score of 75. The patient's weight was $52 \mathrm{~kg}$, and the total IgE level, measured by the CAP system (Phadia, Uppsala, Sweden) was 1304 kU/L. IgE measurement was done in October, when the patient was not exposed to grass and Parietaria pollen in her living area. This level exceeded the maximum IgE level for treating asthma with omalizumab (which is stated in $700 \mathrm{kU} / \mathrm{L}$ ) but was far lower than that previously reported in patients with AD treated with omalizumab [17-19]. Omalizumab was administered in a compassionate use, as approved by the local Ethical Committee, and after obtaining written informed consent from the patient.

The treatment consisted of a dose of omalizumab $375 \mathrm{mg}$ every two weeks. Following the second administration the patient had no more asthmatic symptoms, therefore the dose reduction of symptomatic drugs was started, with a progressive withdrawal of fluticasone, then salmeterol, and finally montelukast: after three months the patient did not need any drug for asthma control. Only sublingual immunotherapy with grass and Parietaria pollen was maintained. In the same period a significant decline in AD severity was observed, with a progressive decrease of SCORAD. Five months later AD was totally cured.

\section{Discussion}

$\mathrm{AD}$ is a common skin disease in childhood, while it is quite rare in allergic adults. The elevated and persistent production of $\operatorname{IgE}$ antibodies plays an important role in this multifaceted disease [21], making AD a possible target of anti-IgE treatment. The data for this indication is limited. A first study on three adult patients (mean age 39 years) with severe AD treated for four months with a dose of $450 \mathrm{mg}$ every other week - that is, exceeding the current maximum recommended dose - failed to demonstrate any benefit [17]. On the contrary, positive results were observed in three children (mean age 11 years) with severe AD who did not answer to any previous treatment [18], and in a series of seven patients (two children and five adults, mean age 31 years) treated with omalizum$\mathrm{ab}$ for persistent uncontrolled asthma associated with AD since early childhood [19]; two patients had a severe, five a moderate, and one an initial stage of disease. In the two positive studies, recommended doses according to individual weight and IgE level were used, except for a 13-year-old child with a serum IgE level of $6120 \mathrm{IU} / \mathrm{ml}$ who was treated with the $450 \mathrm{mg}$ dose.

The level of total IgE is a critical issue, considering that the three patients in the unsuccessful study had a mean starting IgE level of 17.600 $\mathrm{IU} / \mathrm{ml}$ [17] compared to a mean IgE level of 3600 $\mathrm{IU} / \mathrm{ml}$ in the paediatric study [18], and of 1060 $\mathrm{IU} / \mathrm{ml}$ in the positive study on adults and children [19]. Our patient had a starting level of about 1300 $\mathrm{IU} / \mathrm{ml}$ and achieved a clear benefit on $\mathrm{AD}-$ and asthma as well - by the standard maximum recommended dosage of $375 \mathrm{mg}$ every two weeks. This allowed the withdrawal of all drugs, except allergen immunotherapy.

The available data on omalizumab in $\mathrm{AD}$ is not able to indicate the optimal level of IgE predicting a positive response to treatment. Higher doses of omalizumab in patients with AD should be evaluated, also considering that the suggested limit level of $700 \mathrm{IU} / \mathrm{ml}$ when applied to AD is likely to be found in mild AD, which does not justify such expensive biologic therapy [22]. Treatment with omalizumab seems warranted in patients with concomitant severe asthma and AD, as in our case report, in whom the progressive withdrawal of all drugs used to treat the two diseases lead also to a pharmaco-economic positive balance. Well-designed controlled trials are needed to explore the optimal level of IgE predicting a positive response to treatment, comparing patients with different $\mathrm{IgE}$ levels.

\section{References}

1. Ishizaka K, Ishizaka T, Hornbrook MM. Physico-chemical properties of human reaginic antibody. IV. Presence of a unique immunoglobulin as a carrier of reaginic activity. J Immunol 1966; 97: 75-85.

2. Burrows B, Martinez FD, Halonen M, et al. Association of asthma with serum IgE levels and skin-test reactivity to allergens. N Engl J Med 1989; 320: 271-7.

3. Pastorello EA, Incorvaia C, Ortolani C, et al. Studies on the relationship between the level of specific IgE antibodies and the clinical expression of allergy: I. Definition of levels distinguishing patients with symptomatic from patients with asymptomatic allergy to common aeroallergens. J Allergy Clin Immunol 1995; 96: 580-7.

4. Ownby DR. Clinical significance of immunoglobulin E. In Adkinson NF, Yunginger JW, Busse WW, Bochner BS, Holgate ST, Simons FER (eds). Middleton's Allergy. Principles and practice. St. Louis, Mosby, 2003, pp. 1087-103.

5. Presta LG, Lahr SJ, Shields RL, et al. Humanization of an antibody directed against IgE. J Immunol 1993; 151: 2623-32.

6. Schulman ES. Development of a monoclonal anti-immunoglobulin E antibody (omalizumab) for the treatment of allergic respiratory disorders. Am J Respir Crit Care Med 2001; 164: S6-11.

7. Walker S, Monteil M, Phelan K, et al. Anti-IgE for chronic asthma in adults and children. Cochrane Database Syst Rev Apr 2006; 19 (2): CD003559.

8. D'Amato G, Bucchioni E, Oldani V, Canonica GW. Treating moderate-to-severe allergic asthma with a recombinant humanized anti-IgE monoclonal antibody (omalizumab). Treat Respir Med 2006; 5: 393-98.

9. Winchester DE. Omalizumab for asthma. $N$ Engl J Med 2006; 355: 1281-2.

10. Busse WW, Massanari M, Kianifard F, Geba GP. Effects of omalizumab on the need for rescue systemic corticosteroid treatment in patients with moderate-tosevere persistent IgE-mediated allergic asthma: a pooled analysis. Curr Med Res Opin 2007; 23: 2379-86.

11. Global Initiative for Asthma (GINA), Global strategy for asthma management and prevention. Available at: www.ginasthma.com, accessed June 13, 2007.

12. Casale TB, Condemi J, LaForce C, et al. Effect of omalizumab on symptoms of seasonal allergic rhinitis: a 
randomized controlled trial. JAMA 2001; 286: 295667.

13. Chervinsly P, Casale T, Townley R, et al. Omalizumab, an anti-IgE antibody, in the treatment of adults and adolescents with perennial allergic rhinitis. Ann Allergy Asthma Immunol 2003; 91: 160-7.

14. Vignola AM, Humbert M, Bousquet J, et al. Efficacy and tolerability of anti-immunoglobulin E therapy with omalizumab in patients with concomitant allergic asthma and persistent allergic rhinitis: SOLAR. Allergy 2004; 59: 709-17.

15. Nagakura T, Ogino S, Okubo K, et al. Omalizumab is more effective than suplatast tosilate in the treatment of Japanese cedar pollen-induced seasonal allergic rhinitis. Clin Exp Allergy 2008; 38: 329-37.

16. Leung DY, Sampson HA, Yunginger JW, et al. Effects of anti-IgE therapy in patients with peanut allergy. $N$ Engl J Med 2003; 348: 975-6.
17. Krathen RA, Hsu S. Failure of omalizumab for treatment of severe adult atopic dermatitis. $J$ Am Acad Dermatol 2006; 53: 338-40.

18. Lane JE, Cheyney JM, Lane TN, et al. Treatment of recalcitrant atopic dermatitis with omalizumab. $J \mathrm{Am}$ Acad Dermatol 2006; 54: 68-72.

19. Vigo P, Girgis KR, Pfuetze BL, Critchlow ME, Fischer $\mathrm{J}$, Hussain I. Efficacy of anti-IgE therapy in patients with atopic dermatitis. $J$ Am Acad Dermatol 2006; 54: 168-70.

20. Spector SL, Tan RA. Effects of omalizumab on patients with chronic urticaria. Ann Allergy Asthma Immunol 2007; 99: 190-3.

21. Leung DY, Bieber T. Atopic dermatitis. Lancet 2003; 361: 151-60.

22. Beck LA, Saini S. Wanted: a study with omalizumab to determine the role of IgE-mediated pathways in atopic dermatitis. J Am Acad Dermatol 2006; 55: 540-1.

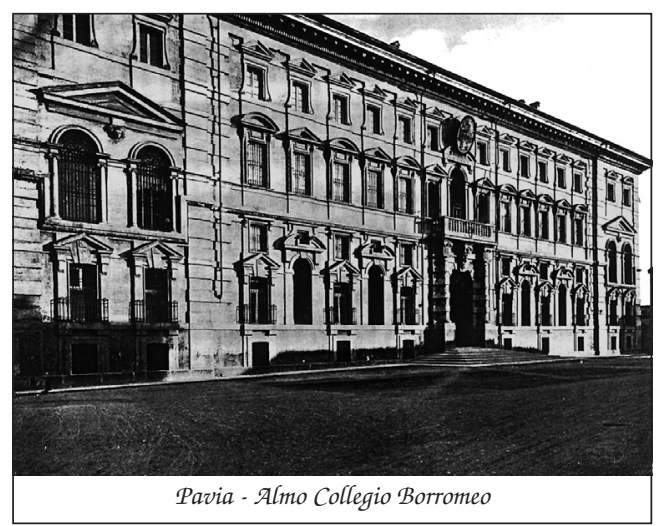

